\title{
Incentive Contract Design for Online Supply Chain Finance
}

\author{
Tu Xiang ${ }^{1,2}$; Yang Qifeng ${ }^{1}$; Song Ping \\ 1. School of Economics, Wuhan University of Technology, Hubei Province Wuhan 430000; \\ 2. College of Information Engineering, Hubei University for Nationalities, Enshi, Hubei Province 445000
}

\begin{abstract}
As a financial model innovation, online supply chain finance is undergoing changes in its financing model, credit model and organizational structure. As the dominant party varies, banks are not necessarily the dominant party in financial transactions. Changes took place in the original principal-agent relationship. In the new model, how to design contractual relationships among financial participants becomes an urgent issue to solve. This paper studied the principal-agent relationship between the platform and the bank in the new financial model with the non-financial institution as the dominant party, and the optimization and design of the incentive contract of the financial partner. It offers new ideas to effectively control the credit risk of online supply chain finance.
\end{abstract}

Keywords-online supply chain finance; incentive contract; principal-agent theory; incentive mechanism

\section{INTRODUCTION}

In recent years, as China's e-commerce market expands rapidly, small and medium-sized enterprises are demanding for short-term microcredit. Banks and third-party e-commerce platforms are striving to break through service models to address the financing needs of B2B e-commerce companies. By the end of 2017, there were 8551 small loan companies across the country. Among them, the companies with e-commerce background developed rapidly. Practice indicates that supply chain finance based on B2B e-commerce platform can bridge banks, third-party B2B e-commerce platforms, logistics enterprises and other systems to realize the concentration and efficient synergy of information, logistics and capital flow. While further enriching the basis for granting credit, it provides convenience for network businessmen to raise fund ${ }^{\text {11] }}$.

It can be seen that banks actively seek to collaborate with third-party e-commerce platforms to launch online supply chain financial services, and Internet companies with e-commerce background are actively engaged in financial services, especially for the microcredit business for small and medium-sized enterprises. But it is worth noting that the development of online supply chain finance is not smooth. In 2011, Alibaba terminated its cooperation with China Construction Bank (CCB) and turned to the development of microfinance business. Taking Ali Finance as an example, by the end of 2016, Ali microfinance had lent loans valuing over 800 billion to more than 5 million small and medium-sized enterprises. In 2012, CCB and Bank of Communications also launched their self-operated B2B platforms such as "Shanrong
Business" and "Jiaobohui", in a bid to become independent of third-party B2B platforms.

Currently, the leading party of online supply chain finance (referred to as "platform side") may be a financial institution, a core enterprise, an e-commerce enterprise, or even a small, medium and micro enterprise alliance. How to design contracts between participants to promote sound and stable cooperation is an urgent issue to be addressed.

\section{LITERATURE REVIEW}

Modern supply chain finance originated from supply chain management in the 1980s. In order to break the bottleneck of the capital flow, the financial services industry began to seek to reduce the financial risks by binding the upstream and downstream small and medium-sized enterprises that need finance with the core enterprises, logistics enterprises and third-party intermediaries of the supply chain activities. This kind of credit guarantee has become typical in which social networks are embedded in normal financial systems ${ }^{[2]}$

In addition, supply chain financial innovation activities such as logistics finance and trade finance that are based on traditional supply chain management activities have long been concerned by the academic community ${ }^{[3]}$. Allen $\mathrm{N}$ Berger et al. proposed a new financing framework for small and medium-sized enterprises, and initially proposed the idea of supply chain finance ${ }^{[4]}$. Hu Yuefei pointed out that supply chain finance is the single or quota credit financing business made by the bank to cooperate the bank's short-term financial products and the closed loan operation. The bank judges by specific products in the supply chain and it's the real trade background and lead enterprises' credit level. The certain future cash flow generated by the trade behavior of the enterprise will be the source of repayment ${ }^{[5]}$.

As for the research of controlling the financial risk of supply chain, Li Yixue assorted complex inventory financing risk into systemic risk and non-systematic risk. In the non-systematic risk, credit risk, inventory liquidation risk and operational risk is the key to controlling financial risk ${ }^{[6]}$. Niu Xiaojian and others point out the important source of financial risk in supply chain is the risk of the capital chain ${ }^{[7]}$.

In 2013, driven by the Internet finance, the supply chain finance went online, which matters more with regards to the national economy and the people's livelihood ${ }^{[8]}$. Some studies have proved that the introduction of supply chain finance to e-commerce platform can increase the enterprises' penalty cost, 
collect enterprises' information and share risks. These advantages can improve credit level of the enterprise and increase the success rate of the loan to a certain extent ${ }^{[9]}$

However, SMEs operate not long enough with relatively small capital scale and incomplete financial statements and high uncertainty. Therefore it is hard to measure the hard information of these enterprises ${ }^{[10]}$. This information asymmetry is still the main obstacle of fund raising for the SMEs ${ }^{[11]}$. An effective means of reducing information asymmetry is to establish the trust of the participants, and the contractual relationship is the basis for achieving transaction trust.

Based on the principal-agent theory, this study studies the contractual relationship that constitutes the trust of financial transactions in basic transactions, and proposes the optimal design of the contract of online supply chain financial partners, which provides a new idea for effectively controlling the credit risk of online supply chain finance.

\section{PRINCIPAL-AGENT RELATIONSHIP BETWEEN FINANCIAL INSTITUTIONS AND PLATFORMS}

Unlike traditional supply chain financial services, the online supply chain financial credit model mainly involves four parties and one platform. The four parties are financial institutions, core enterprises, financing companies, third-party logistics companies, while the platform is the online supply chain financial platform. Among them, the financial institution, as the first principal, is the financial service provider; the core enterprise is the financing application participant that usually plays the role of credit guarantee; the third-party logistics enterprise is the assistant of financial service that usually acts as the agent who supervise the property rights. The leading party of the online supply chain financial platform can be financial institutions, core enterprises, logistics enterprises, e-commerce enterprises, and even small and medium-sized enterprise alliances. It also acts as the agent to conduct joint credit review and assist in property rights supervision.

When the platform side is a financial institution, there is no principal-agent relationship between the financial institution and the platform. In addition, the principal-agent relationship between financial institutions and core companies has a long history and is not discussed in this paper. The focus of this paper is the situation where the platform is a non-financial institution, that is, the principal-agent relationship between the financial institution and the platform.

The online supply chain financial platform can grasp the data information of the production and sales, business transactions and financial status of the enterprises that apply for financing and the information can more accurately reflect the credit status of the financing applicants, which are important credit basis. As the financial resources provider, financial institutions are most concerned about the credit status of applicants. When applicants do not master these important credit bases, they hope to cooperate with the platform to better prevent moral risks, keep capital secure, and improve credit review efficiency and success rate. In this principal-agent relationship, the financial institution is the principal and the platform is the agent.
The formation of principal-agent relationship usually relies on contractual constraints. Due to the bounded rationality of the participants, all complex agreements and contracts are inevitably incomplete, which makes most principal-agent relationships uncertain. As independent economic entities, financial institutions and platforms pursue various maximum benefits. The principal-agent relationship between the two may contain information asymmetry and inconsistent objective utility.

\section{InCENTIVE Contract Design of Financial INSTITUTIONS AND PLATFORMS}

The key to designing financial contracts for financial institutions and platform is the interest distribution. The new incentive contract facilitates the reasonable distribution of benefits, reduce information hiding, and maximize the enthusiasm of the participants, so that all parties under the contract can obtain the maximum benefit in the financing project. The main factors that influence the distribution of benefits include input cost, effective effort and risk taking. Although researches have clarified the role of effort in the distribution of benefits, and deemed that more diligent participants can obtain more benefits, this article proposes that only effective efforts can win more benefits. In the online supply chain financing, there is a principal-agent relationship between the financial institution of the lender and the online supply chain financial platform that assists the credit.

The credit model of online supply chain finance is that financial institutions entrust the platform to provide credit data support, and conduct big data analysis according to the connected supply chain management system, logistics management system, and e-commerce system data, and assist in monitoring the financial service process. Considering the particularity of the banking financial system, it is assumed here that the platform side is not connected to the bank. According to the principal-agent theory, the platform acts according to the big data analysis of multiple platform systems, and the financial institution cannot see this "natural" choice. Therefore, the client needs to design the incentive contract to induce the agent to choose the action that is most beneficial to the principal in the natural state.

The credit method for online supply chain finance discussed here is the joint credit grant of the financial institution and the platform. Both of them must input cost, make efforts and undertake risk for the credit review of the financing applicant, but have different priorities according to their own resources. Financial institutions will make more efforts in reviewing the finance and guarantees of the financing applicants, while the platform focus more on reviewing the authenticity, operational capability and supply chain strength of the financing applicants based on multiple platform systems. In the credit review, due to the fact that the input cost, the effective effort and the risk tolerance are different and partially invisible, the effective efforts of both parties or one party may decrease, incurring moral hazard. Given this, a two-dimensional model based on the input cost and effective efforts of both parties is established to study the incentive contract design. The establishment of the basic model draws on the framework of the principal-agent relationship research 
constructed by Shi Jinzhao ${ }^{[12]}$. It incorporates the audit input cost, effective effort and information security risk into the model, which provides a theoretical basis for the design of the optimal incentive contract.

\section{Reasonable Assumption}

(1) The total amount of credit that can be provided by financial institution $\mathrm{A}$ is $\mathrm{L}$, and the margin required for financing companies is I, then the pledge rate $c=\frac{L}{I+L}$.

(2) The input costs of financial institution $A$ and platform B in the credit review are $C_{B}$ and $C_{E}$ respectively.

(3) The effective efforts cost of financial institution A and platform B in the credit review are $S_{B}$ and $S_{E}$ respectively. Assume that the loan success rate $\mathrm{P}$ is only related to effective efforts, then the higher the cost of effective efforts, the higher the effective effort level.

(4) The income distribution ratio of financial institution and platform: $g$ : $(1-g), 0<g \leq 1$.

(5) When the contract is breached, the liquid ratio of the pledge is $h, 0<h \leq 1$, and the platform does not share the pledge.

(6) During the financing cycle, the discounted loan interest rate is $\mathrm{r}$.

Assuming that both financial institutions and platform parties are risk neutral, the expected utility functions of the two are expressed in terms of their respective expected returns:

$$
\begin{aligned}
\mathrm{U}_{\mathrm{B}}=\mathrm{LP}(\mathrm{rg}+1)+\frac{\mathrm{L}(1-\mathrm{P})}{\mathrm{c}} \mathrm{h}-\mathrm{L}-\mathrm{C}_{\mathrm{B}}-\mathrm{S}_{\mathrm{B}} \\
U_{E}=\operatorname{LPr}(1-g)-C_{E}-S_{E}
\end{aligned}
$$

Equation (1) represents the expected return of financial institutions. It is mainly from the interest gains under successful financing and the realized gains of pledges under financing defaults. The entire financing income should show that the financial institution's income is higher than that of the platform, and the income of both should exceed zero.

$$
\mathrm{U}_{\mathrm{B}}>\mathrm{U}_{\mathrm{E}} \geq 0
$$

In equation (1), suppose the minimum return that the financial institution can accept is 0 , that is, let $U_{B}=0$, and then the minimum income distribution ratio that the financial institution can accept can be obtained as $g_{\text {min }}$.

$$
g_{\min }=\frac{\mathrm{L}(\mathrm{c}-\mathrm{h})(1-\mathrm{P})+\mathrm{c}\left(\mathrm{C}_{\mathrm{B}}+\mathrm{S}_{\mathrm{B}}\right)}{\mathrm{rcPL}}
$$

In equation (2), suppose the minimum return that the platform can accept is 0 , and $\operatorname{set} R_{B}=0$, then the highest income ratio $g_{\max }$ of financial institutions that can be accepted by platform can be calculated:

$$
\mathrm{g}_{\max }=1-\frac{\mathrm{C}_{\mathrm{E}}+\mathrm{S}_{\mathrm{E}}}{\mathrm{cPL}}
$$

Only when $1>g_{\max }>\mathrm{g}>\mathrm{g}_{\min }>0$, and $\mathrm{U}_{\mathrm{B}}>\mathrm{U}_{\mathrm{E}}>0$, the financial institution and the platform's participation constraints can be satisfied, and it is possible to conduct financial transactions. In formula (4) and formula (5), when the financial institution is not a platform party, the input cost $C_{B}$ and the effective effort cost $S_{B}$ in the credit review will naturally decrease. Conversely, the platform input cost $C_{E}$ and the effective effort cost $S_{E}$ in the credit review will increase while the $g_{\max }$ decreases.

From this, it is concluded that in the context of online supply chain finance, the platform will certainly gain a higher degree of credit ownership because it provides more credit. The financial institution, such as the bank, can only passively accept entrusted credit, thus obtaining a lower level of income distribution in the cooperation between the two parties.

In addition, the costs $S_{B}$ and $S_{E}$ of the effective efforts made by the financial institutions and the platform to prevent financial risk can be obtained by the formulas (1) and (2).

$$
\begin{gathered}
S_{B}=U_{B}-L P(r g+1)-\frac{L(1-P)}{c} h+L+C_{B} \\
S_{E}=U_{E}-\operatorname{LPr}(1-g)+C_{E}
\end{gathered}
$$

The total credit rate $\mathrm{L}$ and the pledge rate $\mathrm{c}$ in equation (6) are positively related to the effective effort cost $S_{B}$ of the financial institution. From equation (6), it can be concluded that when the total amount of financial credit is larger, or the total loan income is high, the effective efforts of financial institutions are greater. And the cargo pledge rate c increase or reduce the same way as the effective efforts of financial institutions. However, in the big data era, the platform side relies on a large amount of real transaction data to provide platform credit endorsement for financing companies, and a lot of financial services are carried out without the pledge of goods, such as e-commerce order financing. The reduction of the pledge rate $\mathrm{c}$ is inevitable, so is the decrease of effective efforts of financial institutions.

It is concluded that in the big data environment, the platform side can effectively control the credit risk by reducing information asymmetry, and the financial transaction can be achieved even without pledge. The effective investment of the bank increases only when the credit line Lincreases. Its positive correlation with the rate of goods is weakening.

In addition, in the formula (6), the value of the realization rate $h: 0<h \leq 1$, and the greater the value of $h$, the smaller the effective effort of the financial institution. For example, in the case of e-commerce order financing, when a core company promises to repurchase a product, the bank usually agree to lend the money based on the credit guarantee of the core enterprise.

Based on this, it is concluded that in the online supply chain financial model, if a core enterprise provides credit guarantee for the financing party, the effective investment of the financial institution is still the smallest even if the financing party defaults. Given this, what is needed is the supervision mechanism of credit. 
As far as the platform's concerned, the cost of its effective efforts is mainly to invest in the mining, integration or sharing of information from multiple information systems. In today's big data era, more effective data of financial activity participants means greater voice. The same is true for the online supply chain financial activities in the context of specific trade. Obviously, in the data pledge business launched by banks at this stage, production data, business data, supply chain data, or e-commerce transaction data, can all become proof of loan decisions for the financial institution.

Combining the cooperative game theory and formula (7), we find that the platform side is obviously the one that holds more big data under the joint credit model of the platform and the financial institution. Therefore, if the platform makes more effective efforts, it will have greater power to speak and right to distribute income in financial activities. This is different from the traditional supply chain finance in which banks are dominant and have absolute discourse power.

Based on this, it is concluded that the greater the total credit amount, or the higher the total loan income, the greater the effective efforts of the platform. In this way, the platform has greater dominance and voice of the income distribution while those of the financing institution will be weakened.

From the four conclusions obtained, we can see that financial institutions as loan providers are less dominant and their income are decreasing. However, if the level of income is too low, the financial institutions will be less willing to participate in credit transactions, which will inevitably intensify the financing predicament of small and medium-sized enterprises.

Therefore, in the case of information asymmetry, if the financial institutions have sufficient funds, the more dominant platform will encourage financial institutions to make effective efforts, and encourage the deep integration of platform companies and financial institutions through the incentive mechanisms.

\section{CONCLUSION}

This paper discusses the principal-agent relationship between the platform which is non-financial institution and the financial institution in the context of the joint credit of the financial institution and the platform, and studies the impact of the input cost and effective efforts on the two parties' benefits. It contributes to designing incentive contracts. The main findings are as follows.

(1) In the context of online supply chain finance, the platform will strive for greater credit ownership because it provides more credit. However, the financial institution, such as the bank, can only passively accept the fact of entrusted credit, so it gets the lowest income distributed in the cooperation between the two parties. Banks are also actively seeking to become a platform to gain more revenue, which is also the driving force behind many banks' B2B e-commerce business, that is, to get rid of the dependence on the platform in the online supply chain financial business, and strive for more dominance and benefits.
(2) Under the background of online supply chain finance, the platform effectively controls the credit risk through information asymmetry, and the positive correlation between the financial transaction and the cargo pledge rate is weakened. At this time, the effective efforts of the bank only increase when the credit line L rises.

(3) In the order financing mode, if the core enterprise agrees to repurchase, the liquidity ratio of the pledge is $h=1$. At this time, even if the financing party defaults, the effective investment of the financial institution is still the smallest.

(4) In the case of information asymmetry, the platform will turn to encourage financial institutions to make effective efforts, and through the establishment of incentive mechanisms to improve efficiency, reduce costs, and achieve win-win cooperation.

Subsequent research needs to further discuss and compare the different situations of the leaders of the online supply chain financial platform. Meanwhile, the financial institutions and platforms considered in this paper are completely reasonable. Subsequent research needs to discuss the "Co-opetition" and incentive with the bounded rationality.

\section{REFERENCES}

[1] Guo Ju'e, Shi Jinzhao, Wang Zhixin. On Evolution and Risk Management of Online Supply Chain Financial Model Based on Third-Party B2B Platform [J]. Journal of Business Economics, 2014(1):13-22.

[2] Cao Tingqiu, Liu Haiming. Negative effects of credit guarantee networks: transmission mechanisms and institutional incentives [J]. Journal of Financial Research, 2016(1):145-159.

[3] More D, Basu P. Challenges of supply chain finance: A detailed study and a hierarchical model based on the experiences of an Indian firm [J]. Business Process Management Journal, 2013, 19(4):624-647(24).

[4] Berger A N, Udell G F. A more complete conceptual framework for SME finance [J]. Journal of Banking \& Finance, 2006, 30(11):2945-2966

[5] Hu Yuefei, Huang Shaoqing. Supply Chain Finance: Background, Innovation and Concept Definition [J]. Research on Financial and Economic Issues, 2009(8):76-82.

[6] Li Yixue. Supply chain financial risk assessment [J]. Journal of Central University of Finance \& Economics, 2011,10: 36-41.

[7] Niu Xiaojian, Guo Dongpeng, Qiu Xiang et al. Risk Measurement and Management of Supply Chain Financing-An Empirical Study Based on Bank of China Transaction Data [J]. Journal of Financial Research, 2012(11):138-151.

[8] Song Hua, Chen Sijie. The Evolution of Supply Chain Finance and Internet Supply Chain Finance: A Theoretical Framework [J]. Journal of Renmin University of China, 2016, 30(5):95-104.

[9] Zhao Yue, Tan Zhibo. E-commerce, Bank Credit and Small and Medium-sized Enterprises Financing-A Theoretical Model Based on Information Economics [J]. Economic Research Journal, 2012, 07:99-112.

[10] Roberts M R. The role of dynamic renegotiation and asymmetric information in financial contracting [J]. Journal of Financial Economics, 2015, 116(1):61-81.

[11] Jiang J, Li Z, Lin C. Financing Difficulties of SMEs from Its Financing Sources in China [J]. Journal of Service Science \& Management, 2014, 07(3):196-200.

[12] Shi Jin zhao, Guo Ju'e, Yan Wenjun. On Incentive Contract of Bank and B2B Platform in Online Supply Chain Finance [J]. Journal of Management Sciences, 2015(5):79-92. 